\title{
Ariel Guiance (dir.), La influencia de la historiografía española en la producción americana. Madrid, Valladolid: Instituto Universitario de Historia Simancas, Marcial Pons, 2011, 207 págs.
}

Resulta interesante la aparición de una obra sobre las relaciones entre la historiografía española y la americana, tema dominado todavía por impresiones generales y sobre el que no existen reflexiones ni investigaciones de conjunto, más allá de aproximaciones de tipo biográfico, o a temas como el exilio y la proyección cultural en América de la Junta para Ampliación de Estudios. ${ }^{1}$ La razón estriba precisamente en la naturaleza de su comunicación a lo largo del siglo XX, resultado a fin de cuentas de las actitudes políticas y culturales entre dichos ámbitos. Según Ariel Guiance, coordinador del presente conjunto de trabajos, la inicial aproximación mutua a comienzos del XX, favorecida por la mirada hacia lo hispano de algunos movimientos nacionalistas americanos y el despliegue cultural español en América, fue interrumpida por la Guerra Civil española, cuando, al tiempo que España se sumía en el aislamiento internacional, América recibía las aportaciones personales del exilio español. A partir de aquí, solo la renovación de la historiografía española, y la evolución de la latinoamericana habrían permitido en las dos últimas décadas sobre todo un creciente diálogo, ahora ya sobre preocupaciones de contenido historiográfico. Junto a ello, Guiance anota también importantes variables a tener en cuenta, como la actitud española hacia América, los acontecimientos conmemorativos, las trayectorias personales de determinados historiadores, o la labor editorial de empresas como Fondo de Cultura Económica o Siglo XXI, con acción a uno y otro lado del Atlántico - y a las que habría que añadir, a nuestro juicio, sus ritmos de desarrollo historiográfico en comparación con el progreso internacional de la disciplina.

Es destacable asimismo que la mayoría de los autores que integran este volumen sean americanos, con la excepción de la española Nuria Tabanera, y que su publicación no forme parte de circunstancias conmemorativas o políticas. Responde más bien a preocupaciones actuales de la historiografía latinoamericana, a sus nuevas formas de sociabilidad y a su mayor comunicación con España, como demuestra el hecho de que el libro proceda de un seminario dirigido por Ariel Guiance en la Universidad de Valladolid. En consecuencia, su objetivo huye de visiones excesivamente generalistas para estudiar la repercusión española en áreas historiográficas específicas americanas y sus factores, sin perder de vista sus conflictivas relaciones, aproximaciones y rechazos, y con la mirada puesta en el actual clima de creciente intercambio científico internacional. De hecho, Guiance concluye que hoy se puede sentir influencia española - como tantas otras - en algunos espacios determinados de la historiografía latinoamericana, y que su porvenir no depende ya de problemas políticos - aunque sigan estando presentes -, históricos o personales, sino de la propia evolución historiográfica. Un porvenir que él valora en términos de "encrucijada" entre el eclipse debido a la fragmentación y atomización de los estudios españoles y problemas como el del mimetismo teórico y acrítico, y su posible incremento como consecuencia del panorama historiográfico surgido tras la crisis de los grandes paradigmas.

\footnotetext{
${ }^{1}$ Un ejemplo en el que se analiza la política cultural de la JAE respecto a América como clave para las trayectorias del exilio intelectual español, en Consuelo Naranjo (coord.), "Monográfico: La Junta para Ampliación de Estudios y América Latina: memoria, política y acción cultural (1907-1939)”, Revista de Indias, 39 (enero-abril 2007).
} 
Los dos primeros trabajos se refieren al exilio español en América, en una perspectiva diferente a la tradicional aproximación biográfica que domina todavía este tema. Ariel Guiance examina la acogida de Sánchez Albornoz en Argentina como resultado de su coincidencia metodológica y temática con una incipiente historiografía profesional que buscaba en el pasado medieval hispano sus orígenes en un momento de configuración identitaria nacional a principios del siglo XX. Se trata de una interpretación interesante, que explica la aparición de la singular rama de investigación medievalista sobre la Castilla medieval en Argentina a través de la confluencia entre el personalismo de Sánchez Albornoz, cuyas preocupaciones sobre la historia de España no variaron un ápice en el exilio, y el contexto sociocultural argentino. A pesar de señalar que este arraigo tampoco fue un camino fácil, muestra también cómo los inicios del medievalismo argentino estuvieron fuertemente marcados, tanto en temas, como en métodos y relaciones con historiadores españoles, por las inquietudes básicas de Sánchez Albornoz. Para Guiance, no es hasta los últimos treinta años cuando los procesos de renovación historiográfica argentino y español, de recepción de corrientes internacionales y universalización de temáticas permitan hablar de la existencia de un mayor diálogo mutuo basado en criterios historiográficos propios, y no meramente personales. El resultado para este autor es un panorama de interacciones más complejo, como demostraría el hecho de que algunos temas o historiadores tengan más eco en Argentina que en la Península, y que existan diferencias interpretativas en terrenos como el de la historia de las mentalidades. De ahí que, a la hora de preguntarse por el papel actual del medievalismo español en Argentina, Guiance llame la atención sobre el escaso potencial internacional de la historiografía española, a causa de su falta de síntesis, la fragmentación de sus estudios y la ausencia de plataformas editoriales de mayor alcance.

Uno de los argumentos de Guiance es que mientras Sánchez Albornoz fue bien admitido en Argentina, Américo Castro no corrió con la misma suerte debido a sus polémicas dialécticas con la intelectualidad bonaerense. Como es sabido, Castro recalaría finalmente en Estados Unidos, donde, según señala el medievalista estadounidense Simon R. Doubleday, goza todavía hoy de buen predicamento. ${ }^{2}$ A diferencia del anterior, el trabajo que presenta aquí Doubleday no trata relaciones o trayectorias historiográficas. Más bien, el autor toma como punto de partida el uso actual que hacen autores, como María Rosa Menocal, de su concepto de convivencia, en un contexto de interés general por los fenómenos de hibridación cultural y por sus posibilidades en la investigación histórica, así como en marco del debate público sobre la tolerancia y el fundamentalismo abierto tras el 11-S. ${ }^{3}$ Ahora bien, el autor recoge fundamentalmente las críticas a la utilización de dicho concepto aplicado al medievo hispano procedentes de los nuevos investigadores del tema en Estados Unidos, quienes, apoyados en los estudios coloniales, rechazan el marco teórico nacional y esencialista propio de Castro, para observar las interacciones específicas y locales entre diferentes grupos religiosos. Doubleday ilustra estos nuevos análisis a través de los trabajos publicados por Maya Saifer y Nadia Altschul en el reciente Journal of Medieval Iberian

\footnotetext{
${ }^{2}$ El exilio de Américo Castro y su importancia para el hispanismo norteamericano en G. Pasamar, Apologia and Criticism. Historians and the History of Spain, 1500-2000 (Bern: Peter Lang, 2010), 205221.

${ }^{3}$ Por ejemplo, M. R. Menocal, The Ornament of the World. How Muslims, Jews and Christians Created a Culture of Tolerance in Medieval Spain (Boston: Little Brown and Co., 2002).
} 
Studies, revista sintomática de las nuevas perspectivas de este medievalismo. ${ }^{4}$ La primera autora, dentro de una postura de oposición a la ocupación de Irak, insiste en la importancia de la colonización interna para entender las relaciones cristiano-judías, además de analizar las dimensiones contradictorias de la coexistencia a partir de la noción de poder y hegemonía cultural. En una línea similar sitúa Doubleday el trabajo de Altschul, también fruto de la reflexión sobre problemas políticos actuales. Esta historiadora demostraría la utilidad del análisis poscolonial en la Iberia medieval para repensar el énfasis que Castro pone en el contacto cultural, a través de una aproximación crítica a la diversidad cultural resultante del contacto entre colonizadores y colonizados, sus diferentes niveles, y sus relaciones coloniales de hegemonía o resistencia.

El anterior artículo sin embargo, apunta más a cuestiones propias del desarrollo reciente del medievalismo hispanista estadounidense que a la repercusión actual de la obra de Castro. Ésta parece más bien referencial, como demuestra el uso de algún anacronismo en las críticas hacia su obra. Decir que Castro no tuvo en cuenta conceptos como la lucha de clases o el género es un claro ejemplo (p. 73), que remite además al problema de la recuperación de historiadores desde el presente sin tener en cuenta su contexto historiográfico. El mismo Doubleday en definitiva es consciente de ello, puesto que acaba por justificar esta pretendida resonancia actual de Castro no por su obra, sino por el atractivo de su postura intelectual pública entre una nueva generación de académicos estadounidenses comprometidos con la realidad política y social, y la defensa del valor ético de la historia en el presente. Por otro lado, el trabajo nos emplaza ante cuestiones interesantes necesitadas de mayor investigación, como las líneas de evolución del medievalismo hispanista norteamericano, sus bases teóricas, sus plataformas institucionales o sus redes de sociabilidad, tanto con la historiografía española como con el medievalismo latinoamericano. O, por ejemplo, véase también el amplio tema de las relaciones entre los Latin-American Studies norteamericanos y España, sobre el que por cierto esta obra no hace ninguna referencia, y que nos parece debe ser transversal para cualquier investigación sobre estos temas.

Los dos siguientes trabajos abandonan el terreno del exilio en América, y del medievalismo. El primero es un balance de estudios y perspectivas de investigación de la historiografía sobre tema ibérico en México, en el que se cuestiona la referencia del Estado-Nación desde el punto de vista de la nueva sociabilidad académica internacional. Su autor, Óscar Mazín, plantea la necesidad de estudiar elementos de largo recorrido temporal, en particular procesos enraizados en la Península y que se traducen en América, tales como la movilidad espacial y social, la presencia de las ciudades, y la tradición jurídica. Para dicho autor, el declive del marco nacional, el interés comparativo, la existencia de una comunidad académica más internacional y la renovación de la historia del derecho - y aquí sí cita la repercusión de Tomás y Valiente y Bartolomé Clavero -, habría replanteado la historia política de los siglos XVI y XVIII a partir del concepto de monarquías compuestas desarrollado por John Elliott. ${ }^{5}$ Este último permite, para Mazín, apreciar la monarquía hispana como un conjunto de administraciones interrelacionadas e incluso a veces contradictorias, además de

\footnotetext{
${ }^{4}$ M. Soifer, "Beyond Convivencia: critical reflections on the historiography of interfaith relations in Christian Spain”, Journal of Medieval Iberian Studies, 1:1 (2009), 19-35 y N. R. Altschul, “The future of postcolonial approaches to medieval Iberian studies”, Journal of Medieval Iberian Studies, 1:1 (2009), 517.

5 J. H. Elliott, “A Europe of Composite Monarchies”, Past and Present, 137 (1992), 48-71.
} 
comparar sus diferentes procesos de incorporación territorial y política. Según Mazín, la historiografía mexicana se habría integrado en este nuevo panorama a mediados de los años noventa, llevada por la necesidad de abrir horizontes, por la convicción de que el estudio de las Indias no puede prescindir del proceso global de integración de todos los dominios de la monarquía, y por la aparición de una nueva sociabilidad y comunicación académica. Su punto culminante sería la aparición en 2004 de la red internacional de investigación sobre las monarquías ibéricas Columnaria, en la que el grupo mexicano, dirigido por el propio autor, tiene por objeto el estudiar la incorporación territorial de las Indias occidentales a través de su estatuto jurídico y político, la comparación con Europa y las continuidades medievales. ${ }^{6}$

El venezolano Arturo José Almandoz aborda en el siguiente capítulo la influencia española en la historiografía urbana latinoamericana, aunque lo que hace es describir más bien su evolución disciplinar desde mediados del siglo XX, la cual discurre en paralelo al desarrollismo y la influencia de la teoría de la dependencia. Su idea es que hasta los años ochenta - cuando la renovación de la historiografía urbana en España coincide con el agotamiento de las teorías anteriores en Latinoamérica y el tratamiento de aspectos más espaciales y territoriales -, no se dieron las condiciones para el cruce de influencias. A ello habría que añadir el clima de las celebraciones del 92 y su actividad patrocinadora de eventos, publicaciones e instituciones. Como resultado, dice el autor, España habría acentuado su papel organizador de reuniones científicas, y centro editorial y traductor, al tiempo que se configuraba una plataforma de interés común en el plano epistemológico e institucional, potenciada por estudios interdisciplinarios, por el V Centenario y por la bonanza económica de una España integrada en la Comunidad Europea. Aquí radica precisamente el punto fuerte de este trabajo, al poner el acento en el papel de la política cultural desarrollada como consecuencia del V Centenario.

Ahora bien, el artículo que plantea algunas dudas sobre su encaje con el tema general de la obra, es el de Beatriz Inés Moreyra sobre las propuestas e influencia en América de la obra de François-Xavier Guerra, si bien la autora justifica su elección por su carácter renovador y trasmisor de la historiografía francesa en Latinoamérica. Aunque Guerra nació en Vigo, en nuestra opinión no pasa de ser un dato anecdótico, puesto que desarrolló toda su carrera académica dentro del mundo cultural e institucional francés. Dicho esto, es cierto que esta historiadora argentina describe de modo muy interesante sus rasgos metodológicos, como representante del revisionismo francés en la línea de François Furet o Maurice Agulhon, y como cultivador de "una historia conceptual de lo político, que es, a la vez, historia social de las representaciones aplicada a la política” (p. 154). ${ }^{7}$ Sintetiza bien igualmente la interpretación de que las independencias fueron parte de un único proceso revolucionario personificado en la desintegración de la monarquía absoluta y el paso acelerado a la modernidad, y lo que significa la ruptura liberal española en el surgimiento de las repúblicas hispanas. Pero al

\footnotetext{
${ }^{6}$ http://saavedrafajardo.um.es/WEB/HTML/inicio.html?Open

7 Sin embargo, es cuestionable la denominación de revisionistas al conjunto de las nuevas historias aparecidas desde el 68, como sugiere Pereyra (p. 138). Ello nos lleva a notar también la disparidad de usos de este concepto, con la consecuencia de que ha perdido todo su significado. En esta misma obra por ejemplo, se utiliza también para hablar del revisionismo de la historiografía argentina a principios del XX. Un estudio breve sobre el concepto en relación con los problemas de la memoria, y que desaconseja su utilización, en E. Traverso, El pasado, instrucciones de uso. Historia, memoria, política (Madrid: Marcial Pons, 2007), 94-101.
} 
mismo tiempo la autora plantea su obra como un todo, sin tan apenas alusiones al contexto intelectual y cultural galo, y por tanto margina cuestiones esenciales como los efectos del bicentenario de la Revolución francesa, ciertas problemáticas como la recepción de Guerra en España o América, o el tema de la introducción de la historiografía francesa en América Latina. ${ }^{8}$ Es de agradecer no obstante que Moreyra plantee las ideas que hoy todavía perviven del autor, y las críticas dirigidas al reduccionismo del modelo tradición-modernidad, el descuido de procesos endógenos o la idea de que el liberalismo iberoamericano proceda fundamentalmente del español. Sin embargo, al eludir el contexto historiográfico, la autora trasmite una visión hagiográfica de François-Xavier Guerra o excesivamente categórica (pues lo considera el introductor de la historia política cultural en Latinoamérica), o demasiado inclinada a verlo como el responsable de una deriva hacia el estudio de procesos de modernidad en lugar de a los tradicionales de independencia. ${ }^{9}$

Por último, el artículo de la profesora en la Universidad de Valencia Nuria Tabanera aborda el camino contrario, es decir, la recepción de la historiografía latinoamericana en España, aunque sólo en su versión contemporaneísta. Tras recordar el carácter periférico de ambas historiografías y sus dificultades de evolución y desarrollo respecto a las historiografías más potentes - idea esencial para situar el tema en relación a la evolución de la disciplina -, examina los contactos actuales entre ambas historiografías dentro del amplio proceso de evolución secular del americanismo español. Su interpretación parte de la quiebra que supuso la Guerra Civil tanto para el americanismo liberal español como para sus primeras relaciones con América. A partir de aquí, la institucionalización y fuerte identificación del americanismo español con el franquismo, y su carácter endogámico y aislado del exterior, impedirían su renovación en la historiografía española y sus intercambios con América hasta llegados los años ochenta. De modo paralelo, apunta esta autora, la progresión de la historiografía latinoamericana se vio interrumpida en los años setenta por las dictaduras militares y la crisis económica. La conclusión de Tabanera, en sintonía con el resto de la obra, es que hasta fines de los ochenta no se puede hablar de una coyuntura de contactos personales, institucionales e investigadores fluidos, facilitados por la renovación institucional y metodológica del latinoamericanismo contemporaneísta español, por los fondos y planes asociados al $\mathrm{V}$ Centenario, y por la reconstrucción de las comunidades académicas latinoamericanas afectadas por las dictaduras. Estos elementos constituyen para esta historiadora la base sobre la que se han normalizado a partir de los noventa los contactos e intercambios, hasta poder hablar incluso de influencias americanas en España en aspectos tales como la nueva historia política y la introducción de conceptos como el de "cadena migratoria". ${ }^{10}$

En definitiva, el presente libro es una obra sobre la influencia española en la historiografía latinoamericana que demuestra que ésta ha sido débil, salvo casos excepcionales y muy particulares como el de Sánchez Albornoz en los albores del medievalismo argentino (o Rafael Altamira, por añadir otro ejemplo muy claro). El

\footnotetext{
${ }^{8}$ A modo de ejemplo en este sentido, Fernando J. Devoto, “Itinerario de un problema: Annales y la historiografía argentina, 1929-1965”, Anuario del IEHS, 10 (1995), 161-173.

9 Un estado de la cuestión reciente sobre estos aspectos, Manuel Chust (ed.), Las independencias iberoamericanas en su laberinto. Controversias, cuestiones, interpretaciones (Valencia: Universidad de Valencia, 2010).

${ }^{10}$ Un reciente ejemplo de este diálogo creciente en Carmen González Martínez y Encarna Nicolás Marín (eds.), "Procesos de construcción de la democracia en España y Chile”, Ayer, 79 (2010).
} 
texto evidencia por lo tanto que la idea de "influencia”, expresión a la que dichos estudios apelan sin detenerse en mayores detalles, ha quedado obsoleta (y de hecho, en todos los artículos de este volumen se habla más de relaciones que de influencias). La obra es más bien reflejo de la nueva sociabilidad internacional de la historiografía latinoamericana a través de algunos de sus protagonistas, y de algunas de sus recientes líneas de desarrollo como la nueva historia política. ${ }^{11}$ Aunque han pasado desapercibidos temas elementales para cualquier estudio de relaciones entre estas historiografías a lo largo del siglo XX, el texto sirve de punto de partida para trabajar sobre todos estos aspectos. La más llamativa de esas lagunas es la de Rafael Altamira, sin duda el historiador español con mayor relación con América, además de pionero en la política cultural desarrollada por España en el primer tercio del siglo XX. ${ }^{12}$ Eso sin hablar de su influjo en los Latin-American Studies, o de su exilio mexicano, cuya historia está trabajando en México José Manuel Ledezma. Con todo, además de ofrecer un marco general para el estudio de estas relaciones, el libro apunta algunas cuestiones interesantes para los estudios venideros, tales como las conmemoraciones, que tiene muchas posibilidades de investigación, o el papel de las editoriales. Hay que tener en cuenta que se trata de una obra fruto de un seminario sobre temas tan apenas abordados hasta la fecha y sin la pretensión de agotar todas sus posibilidades. Constituye pues una buena base para emprender investigaciones más profundas, así como para reflexionar sobre las nuevas formas de comunicación internacional de la historiografía latinoamericana y española.

Óscar Adell Ralfas

Universidad de Zaragoza

oadellralfas@gmail.com

Fecha de recepción: 24 de noviembre de 2012

Fecha de aceptación: 5 de diciembre de 2012

Publicado: 31 de diciembre de 2012

Para citar: Óscar Adell Ralfas, “Ariel Guiance (dir.), La influencia de la historiografía española en la producción americana, Madrid, Valladolid: Instituto Universitario de Historia Simancas, Marcial Pons, 2011, 207 págs.”, Historiografías, 4 (julio-diciembre, 2012): pp. 131-136, http://www.unizar.es/historiografias/historiografias/numeros/4/adell.pdf

\footnotetext{
${ }^{11}$ Un estudio sobre la evolución de la historiografía latinoamericana, que ha pasado además desapercibido en España, en Jurandir Malerba, La historia en América Latina. Ensayo de crítica historiográfica (Buenos Aires: Prohistoria ediciones, 2010)

${ }^{12}$ Sobre este aspecto han aparecido recientemente, por ejemplo, Gustavo H. Prado, Rafael Altamira en América (1909-1910). Historia e historiografía del proyecto americanista de la Universidad de Oviedo (Madrid: CSIC, 2008), y Gustavo H. Prado, Las lecciones historiográficas de Rafael Altamira en Argentina (1909): apuntes sobre Ciencia, Universidad y pedagogía patriótica (Oviedo: Universidad de Oviedo, 2010).
} 